\title{
The vectorial organization of the human myocardium is designed for optimal electrical and contractile activity: clinical implications of its alterations
}

\author{
M. Tafani ${ }^{1,2}$, F. Carpi $^{3}$, E. Morgante ${ }^{1}$, A. Russo $^{4}$, A. Carpi $^{5}$, \\ M. Fini ${ }^{2}$, B. Marino ${ }^{1}$, A. Frustaci ${ }^{1} \&$ M. A. Russo ${ }^{1,2}$ \\ ${ }^{1}$ University of Rome, Italy \\ ${ }^{2}$ IRCCS San Raffaele Pisana, Italy \\ ${ }^{3}$ School of Engineering, University of Pisa, Italy \\ ${ }^{4}$ IRCCS Regina Elena, IFO, Italy \\ ${ }^{5}$ University of Pisa, Italy
}

\begin{abstract}
In this paper the organization of the human myocardium is reviewed at the tissue, cellular and molecular levels in order to understand the design that allows highly vectorial activities, such as the contraction of the cardiac pump and the electrical activity underlying its coordination. Amazingly, it appears that twisted helical structures are formed by molecules or by cells that are aimed to produce an efficient and coordinated contractile activity, which is needed for the propulsion of the blood from the North of the atria to the South of the ventricles and then to the blood vessel tree. Mutations of morphogenetic genes, mutations of monomeric proteins, their immature isoforms, and perturbing extraneous molecules can lead to abnormal organizations of crucial supramolecular structures (sarcomeric disarray, alteration of intercalated discs, abnormal gap junctions, misaligned myocardial fibers), which results in an abnormal clinical function. In addition, recent evidences suggest that mutations of specific genes controlling helical structures and the spiraling organization of the heart may contribute to well known malformations, such as transposition of the great arteries.
\end{abstract}

Keywords: heart, chirality, helical structures, nodal, lefty, malformations, morphogenetic damage. 


\section{Cardiac pump organization}

The basic functional unit of the heart is the myocardiocyte, the specialized contractile and conducting cell of the myocardium. The functional efficiency of myocardiocytes is achieved through two aspects of their organization: one at the subcellular level, and the other at the supracellular (tissue and organ) level. In both cases helical and spiraling organization of the lower components are evident and may be described. Briefly, the cardiac pump must actively propel the blood mass from the atrial chamber into ventricles and into the arterial tree. The myocardium is organized as bundles of fibrils that run from the North of the atria to the South of the ventricles following a left-hand spiraling path, which is determined by the interactions among myocardiocytes and the complex interplay with the extracellular matrix (ECM).

\section{The chirality of fibrils is mainly determined by the South/North interactions between myocardiocytes}

At the intercalated discs, myocardiocytes interact forming junctional complexes, including coupling gap junctions. The longitudinal axis (North $\rightarrow$ South) of the individual myocardiocyte is left-hand twisted to adapt (or determine) the spiraling path. Different adhesive molecules, connexins and their isoforms may contribute to achieve spiraling organizations.

\section{The molecular machine of the contraction is constituted of helical structures}

The myocardiocyte sarcomere is the molecular machine that develops the contractile force needed to pull the blood mass from cardiac chambers into the arteries (aorta and pulmonary artery) and to the peripheral tissues. Actin and myosin are the interacting proteins, but only their helical polymers exhibit the ability to slide each other and to hydrolyze ATP to fuel the contractile machine. The organization of actin filaments, myosin filaments and the active polymers of many accessory regulatory and structural proteins of the sarcomere are typically helically arranged (figures 1-4).

\section{Actin polymer interaction leads to the formation of a left-handed twisted thin filament}

Actin is a globular protein that forms a linear polymer that is energetically unstable. A helical conformation renders the individual polymer much more stable; two polymers form typical twisted, left-hand helical filaments that are stable in the cytosol in the physiological conditions (temperature, $\mathrm{pH}$, ionic strength and energy charge) of the cytosol. Accessory and regulatory proteins contribute not only to the function, but also to the stability of the actin filament (figure 1). Native tropomyosin is a filamentous protein; when polymerized, it 
shows two orders of spiralization: a helical arrangement of two monomers and a helical interaction with the stable actin polymeric filament, following the period typical of this structure. The troponin subunits (T,I,C) and tropomyosin polymer regulate the direct interaction between actin and myosin (figure 3 ).

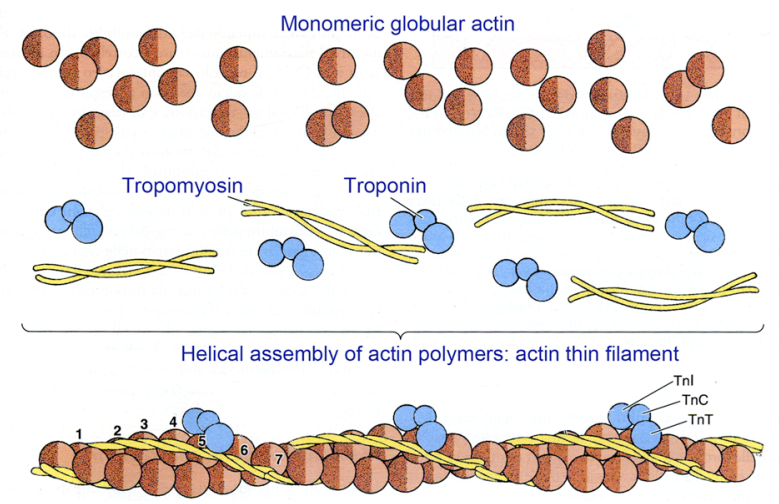

Figure 1: Actin filament helical organization. Globular monomers of actin (G-actin) form polymers (F-actin); their helical assembly results in an actin thin filament that is stabilized by tropomyosin and many other accessory proteins (not shown). Tropomyosin assembly gives rise to a helical polymer interacting with actin filament following its helical path. Troponin ( TnI, TnC, TnT) interacts periodically (each 7 G-actin) with this complex assembly (modified from [7]).

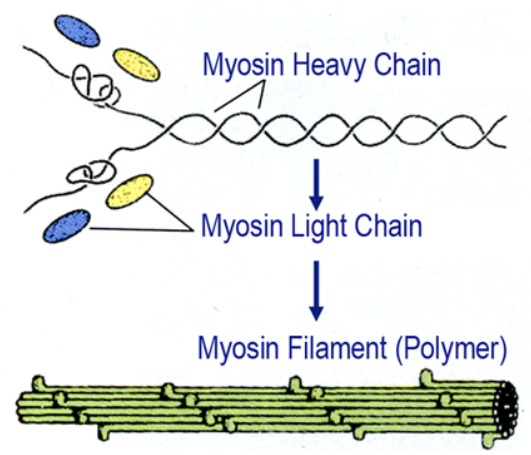

Figure 2: In the myosin filament two order of helical arrangement can be evidenced. The first is observed when the linear domain of $2 \mathrm{MHC}$ are interacting each other. The second originates from the bundling of six molecules of myosin, exposing the two heads on the external surface of the bundle with a complete helical period each six paired heads (modified from [7]). 


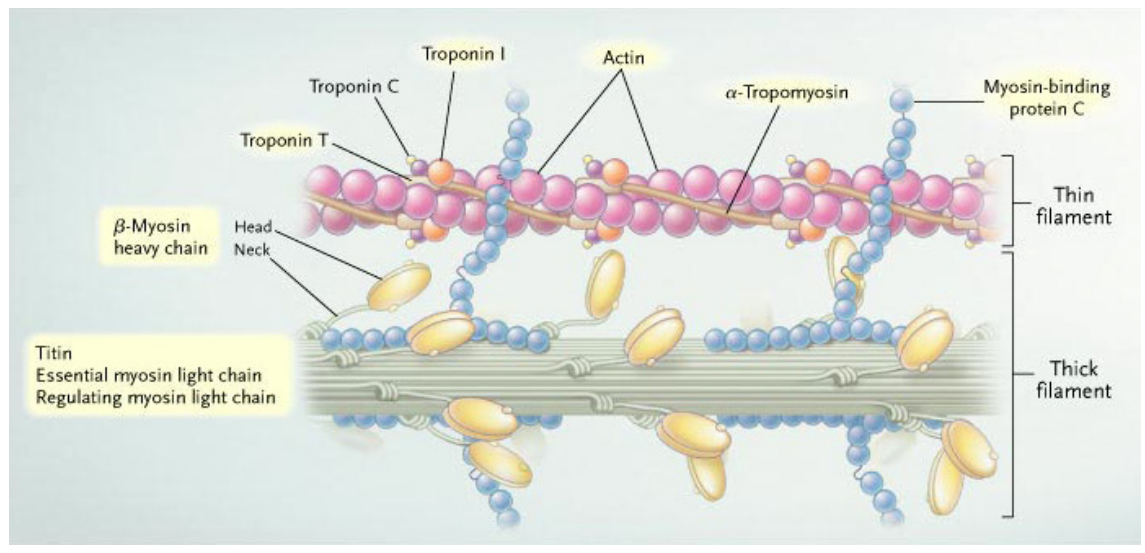

Figure 3: Interactions between actin and myosin filaments. The helical distribution of actin sites for myosin and myosin heads allows the optimal utilization of these structures in a hexagonal array of the filaments.

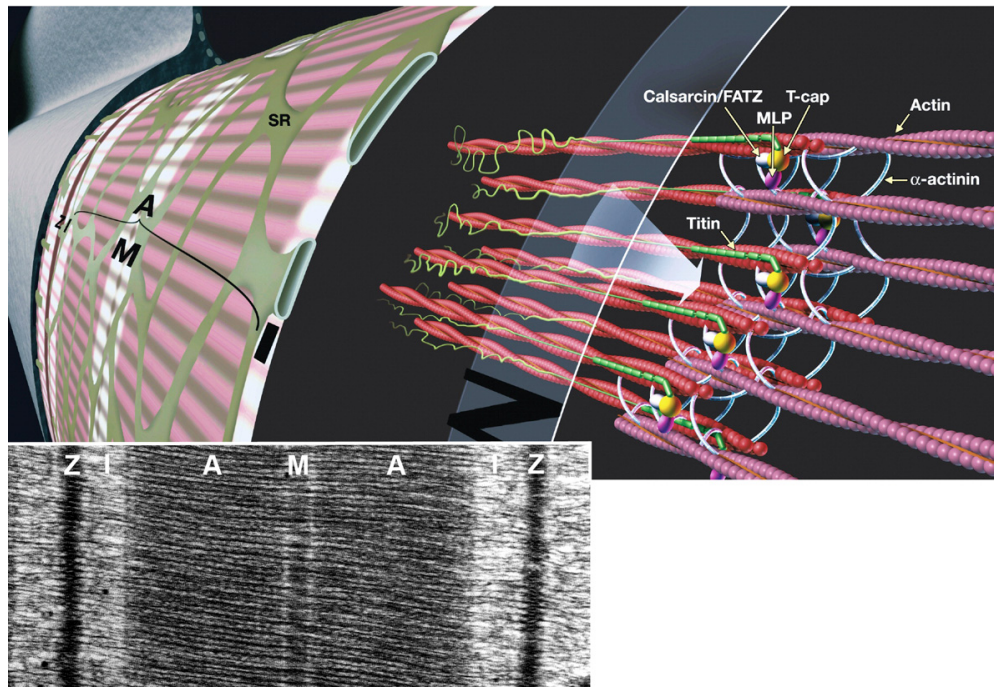

Figure 4: Different interaction of accessory molecules exhibiting helical structures at the level of $\mathrm{Z}$ disc. $\mathrm{Z}$ disc is the anchoring point for thin filaments. $Z$ disc also anchors to the plasma membrane (or sarcolemma) and to the ECM. Alpha-actinin, calsarcin, T-cap, and desmin contribute to the strength of the Z-disc. Mlp are mechanosensor proteins that are able to generate signals in relation to the mechanical stress. Titin is the largest known protein with helical domains that reinforce the actin-filament. The anchorage of the Z-disc to the sarcolemma and ECM is mediated by distrophins and sarcoglycans. 


\section{Myosin thick filament displays two order of helical arrangements}

Myosin is a complex molecule composed of $2+2$ subunits. A couple of myosin light chains (MLC), a globular protein with ATP-hydrolyzing and phosphorylating activity, and a couple of myosin heavy chains (MHCs). MHC subunit exhibits a globular head, a hinge region and a linear domain, which display a helical arrangement when interacting with the homologous domain of the paired subunit. The myosin thick filament is formed by six molecules of myosin exposing at the surface of the bundles the two globular heads forming a complete helical period for each six paired heads. This helical architecture of myosin heads allows the optimal interaction with the active sites on the helical actin polymer (figure 2).

\section{Isoforms of sarcomeric proteins and loss of contractile function: hypertrophy disarray}

Isoforms of adult sarcomeric proteins are present in the adult myocardium allowing the optimal vectorial assembly of the sarcomere along the direction of the stretching and the efficient contractile function. During embryonic and fetal life each sarcomeric protein is temporarily expressed by immature isoforms, usually obtained by alternative splicing, which are physiologically sufficient for
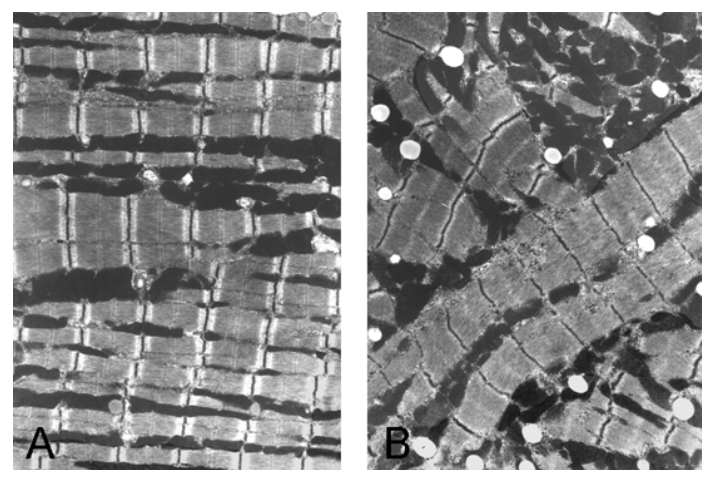

Figure 5: Sarcomeric disarray in myocardial hypertrophy. A. Normal sarcomeric array in a control healthy myocardium. The longitudinal axis of the sarcomeres is aligned along the direction of the contraction. B. Typical disarray in a hypertrophic myocardium (severe hypertrophy due to chronic hypertension). The sarcomeric fibrils and their longitudinal axis are randomly oriented and sometimes perpendicular, reciprocally cancelling their contractile vectors. In these myocardiocytes a large amount of immature isoforms of sarcomeric proteins may be evidenced (from [8]). 
the embryonic life's functional requirements. However, when in adults a continuous functional overload (i.e. a loss-of-function mutations of sarcomeric proteins or hypertension or valvular disease) stimulates sarcomeric gene expression, immature isoforms are overexpressed, leading to a pathological assembly of the sarcomer with disarray and contractile inefficiency (figure 5).

\section{Junctional complex alterations and electrical activity in arrhythmias}

The highly coordinated contractile activity in the heart is basically achieved in two ways: a) a conducting specialized tissue (conducting tissue), formed by modified myocardiocyte ( $\mathrm{P}$ cells, transitional cells, Purkinje cells), which activates the distant segment of myocardium; b) an interaction at the South-toNorth interface of myocardiocytes through the intercalated disc and a lateral interaction through the lateral gap junctions. In addition, the conducting tissue cells are connected by the junctional complex of the intercalated disc, forming, as a result, highly conductive fibers (His bundles). The highly organized junctional complex of the intercalated disc determines not only the electrical and metabolic coupling, but also the architectural conformation to acquire the twisted form of myocardial fibers, along the longitudinal axis (figure 6). Intercalated discs and their different junctions may be modulated, reversibly widened or severely disorganized (figure 7). In the last case electrical conduction and coordination among the different segments of myocardium may be impaired, giving rise to arrhythmias and, possibly, to sudden death.

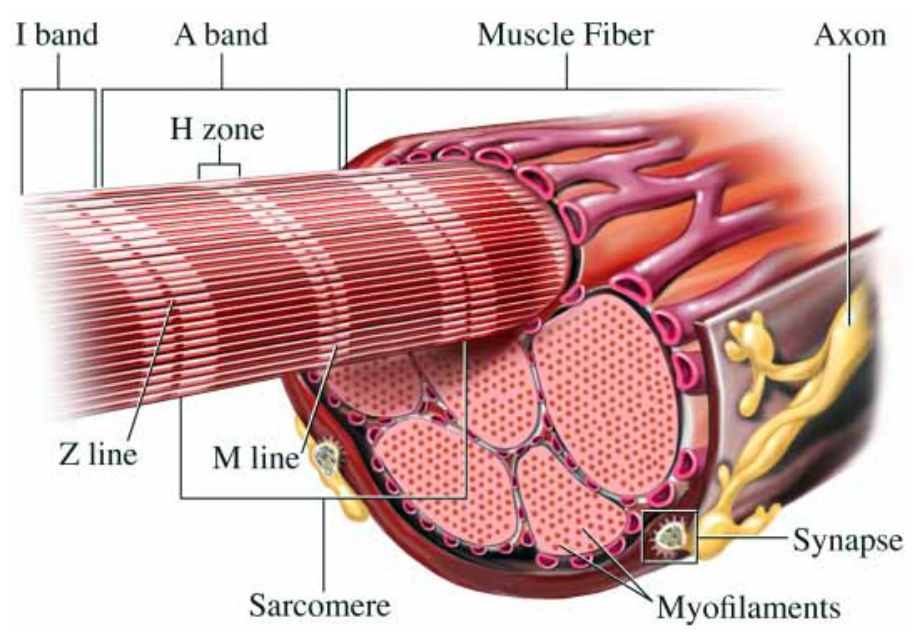

Figure 6: Myocytes of a muscle fiber are aligned along the direction of the contraction, being slightly twisted and following a helical path. 

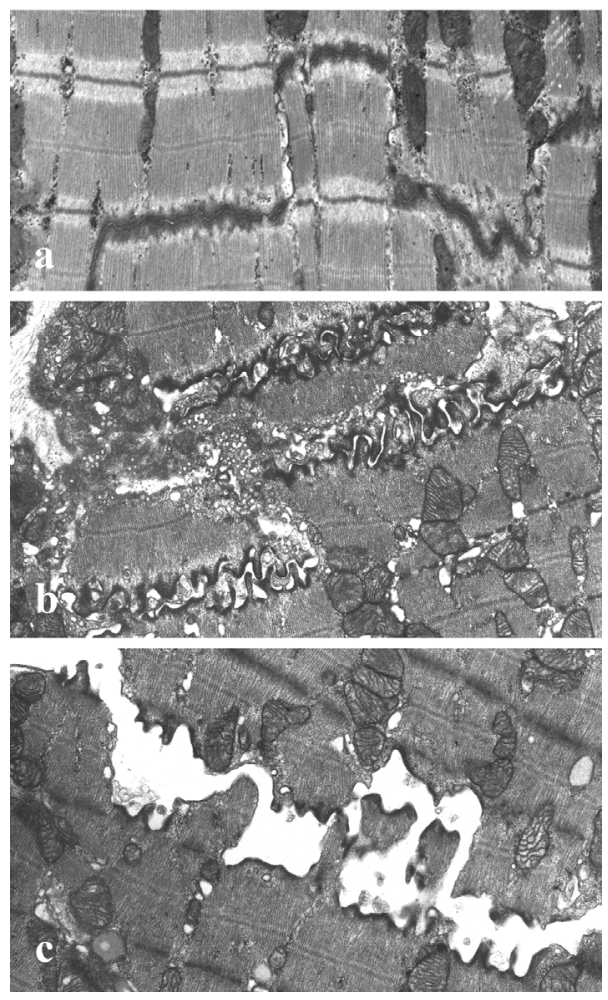

Figure 7: Disorganization of the intercalated disc as a structural basis for arrhythmias. A. Normal ultrastructure of an intercalated disc joining and coupling two myocardiocytes. B. Reversible widening of some component of the junctional complex of the intercalated disc. This is associated with an intracellular high level of c-AMP (in this case produced by histamine) and a transient arrhythmia. The alteration is completely reversible following the decrease of cAMP levels. C. Irreversible and severe disorganization of all the components of the intercalated disc. The experimental treatment was similar to that in the previous figure, followed by a mechanical stretching along the direction of the contraction [9].

\section{Genes involved in left-right asymmetry}

The left-right asymmetry in the heart and its precise interactions with great vessels is established during early morphogenesis under control of Nodal and Lefty, two genes dealing with TGF- $\beta$ signaling [1-4]. These proteins are expressed only in the left segment of the embryo (lateral plate mesoderm) and determine the growth and differentiation of cells that will generate the heart and other left structures [1-3]. Their mutations (with both loss-of-function and gain-of-function) are involved in many complex variants of heterotaxy, including 
dextro-transposition of great arteries with other cardiac anomalies and situs inversus viscerum [5]. The Nodal gene is a member of the TGF- $\beta$ superfamily, which is highly conserved during evolution. More interestingly, an ortholog form of Nodal has been identified in snails where it controls the left-right chirality of their shell coiling [6] (figure 8). The Lefty gene is a morphogene, a member of the TGF- $\beta$ family, with an antagonistic activity to the Nodal gene. Then it is deeply involved in left-right asymmetry determination and may be responsible of many human malformations $[1,5]$. Both genes are active in the early breaking of the initial symmetry of the embryo, with a flow mechanism that is determinant for the speed and direction of the growth and movement of the future myocardiocytes [1].

\section{Final considerations}

Helical structures, spiraling migratory movements and pathways, left/right chirality and the asymmetric architecture of organs and organ packaging are representative examples of how the design of physiological structures, from molecules to organs, may determine their optimal functions. With the information available, we know that a specific design is achieved by different
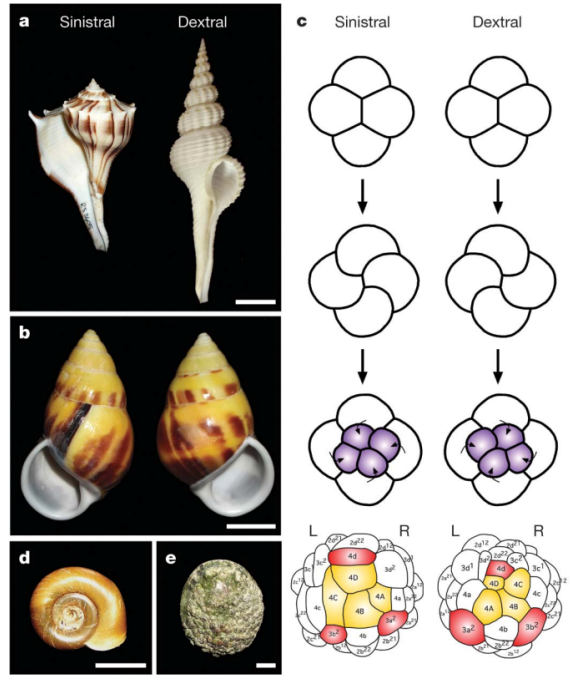

Figure 8: Chirality in snail shell. a. There are species of snail with different chirality: sinistral or dextral. b. The same species may show a dimorphism (sinistral or dextral) in relation to the Nodal variant. c. This diagram shows schematically how the sinistral or dextral asymmetry is achieved, probably in relation to the diffusion (flow hypothesis) of the Nodal product; moreover, the Nodal protein is able to determine the direction, speed and force of each committed cell (early myocardiocytes) (from [6]). 
Table 1: Helical and spiral configurations that can be identified into the heart and other vectorially organized tissues.

\begin{tabular}{|c|c|c|}
\hline Level & Examples of Structures & $\begin{array}{c}\text { Control mechanism for helical } \\
\text { or spiraling or asymmetrical } \\
\text { organization }\end{array}$ \\
\hline Molecular & $\begin{array}{l}\text { Actin, tropomyosin, } \\
\text { troponin, etc. }\end{array}$ & $\begin{array}{l}\text { Primary, secondary, tertiary } \\
\text { protein structure }\end{array}$ \\
\hline Supramolecular & $\begin{array}{l}\text { Actin filaments, myosin } \\
\text { filaments, intermediate } \\
\text { fibrils, sarcomeres, } \\
\text { anchorage structures, etc. }\end{array}$ & $\begin{array}{l}\text { Quaternary protein structure, } \\
\text { interactions with other } \\
\text { proteins; protein subcellular } \\
\text { localization }\end{array}$ \\
\hline Cellular & $\begin{array}{l}\text { Myocardiocytes; uterine, } \\
\text { vascular, intestinal } \\
\text { myocyte; skeletal myocyte, } \\
\text { etc. }\end{array}$ & $\begin{array}{l}\text { Polarity of the cell; shape of } \\
\text { the cell; vectorial organization } \\
\text { of supramolecular structures } \\
\text { (such as sarcomeres) }\end{array}$ \\
\hline Supracellular & $\begin{array}{l}\text { Early chirality of many } \\
\text { types of cells and } \\
\text { asymmetry in cell-to-cell } \\
\text { interactions }\end{array}$ & $\begin{array}{c}\text { North/South cell-to-cell } \\
\text { junctions; lateral cell-to-cell } \\
\text { junctions; connexins; } \\
\text { intercalated disc junctional } \\
\text { complexes; cilium; interaction } \\
\text { with ECM }\end{array}$ \\
\hline Tissue & $\begin{array}{l}\text { Fibril and fiber architecture } \\
\text { and orientation: chirality in } \\
\text { myocardium, in smooth } \\
\text { muscle with peristalsis } \\
\text { (uterus, intestine, ureters, } \\
\text { urethra, vessels) }\end{array}$ & $\begin{array}{l}\text { Cell orientation; single cilium } \\
\text { movement; interactions with } \\
\text { other cells and with ECM; } \\
\text { vectorial structures: annular } \\
\text { chirality and longitudinal } \\
\text { chirality }\end{array}$ \\
\hline Organ & $\begin{array}{l}\text { Bundles of fibrils and } \\
\text { fibers; interaction with } \\
\text { other structures, such as } \\
\text { vessels, ligaments, etc. }\end{array}$ & $\begin{array}{l}\text { Cell orientation; interaction } \\
\text { with other cells and structures, } \\
\text { laterality and chirality genes } \\
\text { (nodal, lefty, wnt, shh, etc.) }\end{array}$ \\
\hline
\end{tabular}

control mechanisms (see table 1) and that the alterations of such mechanisms may be responsible for important human pathologies and malformation syndromes.

\section{References}

[1] Capdevila, J., Vogan, K.J., Tabin, C.J. \& Izpisúa Belmonte, J.C., Mechanisms of left-right determination in vertebrates. Cell, 101, pp. 9-21, 2000.

[2] Zhou, X., Sasaki, H., Lowe, L., Hogan, B.L. \& Kuehn, M.R., Nodal is a novel TGF-beta-like gene expressed in the mouse node during gastrulation. Nature 361, pp. 543-547, 1993.

[3] Meno, C., Shimono, A., Saijoh, Y., Yashiro, K., Mochida, K., Ohishi, S., Noji, S., Kondoh, H. \& Hamada, H., Lefty-1 is required for left-right 
determination as a regulator of lefty-2 and nodal. Cell, 94, pp. 287-297, 1998.

[4] Saijoh, Y., Oki, S., Ohishi, S. \& Hamada, H., Left-right patterning of the mouse lateral plate requires nodal produced in the node. Dev Biol, 256, pp. 160-172, 2003.

[5] De Luca, A., Sarkozy, A., Consoli, F., Ferese, R., Guida, V., Dentici, M.L., Mingarelli, R., Bellacchio, E., Tuo, G., Limongelli, G., Digilio, M.C., Marino, B. \& Dallapiccola, B., Familial transposition of great arteries caused by multiple mutations in laterality genes. Heart, Nov.20, 2009.

[6] Grande, C. \& Patel, N.H., Nodal signalling is involved in left-right asymmetry in snails. Nature, 457, pp. 1007-10011, 2009.

[7] Junqeira LC, and Carneiro J, Basic histology. Text \& atlas. McGraw-Hill, 2003.

[8] Pontieri GM, Russo MA, Frati L, Patologia Generale, vol.2, Piccin Publ, Padova, 2010.

[9] Russo MA: unpublished, 2010. 